\title{
KIERKERGAARD E COMTE-SPONVILLE: dois posicionamentos acerca do desespero
}

\author{
Gustavo Maciel de Oliveira \\ (Universidade de São Paulo) \\ https://orcid.org/0000-0002-8835-1301 \\ José Américo Bezerra Saraiva \\ (Universidade Federal do Ceará) \\ https://orcid.org/0000-0003-0483-4996
}

\section{RESUMO:}

O presente trabalho tem como meta proceder à análise da relação de contraposição entre o discurso de André Comte-Sponville (1952-) e o do filósofo dinamarquês Kierkergaard (1813-1855) no que tange especificamente ao modo de abordar a paixão do desespero. Com base na análise, podemos dizer que, por considerar o desespero de modo positivo, de maneira oposta à do filósofo dinamarquês, Comte-Sponville se posiciona não só em relação a Kierkergaard, mas também em relação a toda uma tradição do pensamento ocidental. Entendemos que, na malha interdiscursiva que o envolve, o pensamento do filósofo francês ainda se mostra capaz de dialogar com os discursos sobre o desespero tecidos na contemporaneidade, uma vez que, ao euforizar "um aprender a viver sem esperanças", afirma a imagem moderna de um mundo vivido na distopia. Para levar a efeito a análise, nos ancoramos em conceitos extraídos da Análise do Discurso Francesa (MAINGUENEAU, 2008) e da Semiótica Discursiva (GREIMAS; COURTÉS, 1979; SARAIVA, 2012; OLIVEIRA, 2019), tendo em vista as convergências possíveis entre esses dois campos de pesquisa.

PALAVRAS-CHAVE: interdiscursividade; discurso filosófico; desespero; Comte-Sponville. 


\title{
KIERKERGAARD AND COMTE-SPONVILLE:
}

\author{
two positions about despair
}

\begin{abstract}
:
The aim of the present paper is to analyze the contrasting relationship between the discourse of André Comte-Sponville (1952-) and that of the Danish philosopher Kierkergaard (1813$1855)$ with regard specifically to the approach of the passion of despair. Based on the analysis, we can say that, by considering despair positively, as opposed to that of the Danish philosopher, Comte-Sponville stands not only with respect to Kierkergaard but also with respect to a whole tradition of the Western thought. We understand that, in the interdiscursive mesh that surrounds it, the thought of the French philosopher is still capable of dialoguing with the discourses about despair woven in contemporary times, since, by euphorizing "learning to live without hope", he affirms the image modern of a world lived in dystopia. To carry out the analysis, we anchored in concepts extracted from the French Discourse Analysis (MAINGUENEAU, 2008) and Discursive Semiotics (GREIMAS; COURTÉS, 1979; SARAIVA, 2012), considering the possible convergences between these two fields of research. KEYWORDS: interdiscursivity; philosophical discourse; despair; Comte-Sponville.
\end{abstract}

\section{Introdução}

Neste trabalho, começaremos por propor uma aproximação entre alguns elementos teóricos da Análise do Discurso Francesa e outros da Semiótica Discursiva de base greimasiana, tomando como norte a articulação realizada por Saraiva (2012) sobre a relação entre sujeito discursivo e sujeito interdiscursivo. Temos o objetivo de mostrar que, apesar das diferenças metodológicas, as duas áreas podem apoiar-se mutuamente sobretudo no que se refere ao modo como o discurso é concebido, ou seja, como uma "tomada de posição". 
Essa reflexão será acompanhada de uma análise fundamentada em alguns dos resultados obtidos por Oliveira (2019). Este último, ao fazer uma recensão sobre alguns autores que haviam versado sobre o tema do desespero, encontrou uma relação polêmica e interdiscursiva entre dois filósofos: André Comte-Sponville, autor contemporâneo ainda vivo, e Søren Kierkergaard, filósofo dinamarquês do século XIX. Ao se opor ao discurso deste último, Comte-Sponville afirma a imagem de um mundo que nega a utopia e afirma a distopia, o que o torna um filósofo refratário a um "discurso da esperança", que seria representado por Kierkergaard e que estaria ligado a toda uma dada tradição ocidental.

Tal relação polêmica entre discursos nos remete ao tratamento que Maingueneau (1984) aplicou à relação entre o discurso jansenista e o discurso humanista devoto, analisados como posicionamentos em competição no discurso religioso do século XVII. Nesse trabalho, o autor chega a uma estrutura global de coerção semântica que relaciona e determina os dois discursos em sua polêmica. Maingueneau, no nosso entender, depreende dos discursos analisados estruturas elementares de significação (semas contrários) que relacionam esses discursos entre si e os colocam em competição a partir do investimento fórico (euforia e disforia) atribuído, por cada posicionamento discursivo, aos termos contrários da estrutura elementar de significação. Em outros termos, no que é posto em relação pelos dois discursos, o que é visto de modo "positivo" pelos jansenistas é visto de modo "negativo" (contrário) pelos humanistas devotos.

Ressaltamos que essa avaliação fórica se faz acompanhada de uma tradução, uma vez que o discurso jansenista traduz os termos da estrutura elementar da significação contidos no discurso humanista devoto para com ele polemizar, e vice-versa. Sendo assim, a relação de oposição que envolve os discursos em polêmica aparece marcada nos textos que a manifestam, isto é, a presença do outro com o qual um discurso polemiza é fundamental para a constituição das estruturas elementares da significação, e estas, por sua vez, traduzidas e avaliadas, manifestam-se nos textos que promovem a polêmica. No decorrer da articulação a ser realizada na seção a seguir, e, ao partirmos para a análise em seção posterior, veremos que é algo desse tipo que acontece no jogo interdiscursivo levado à frente por Comte-Sponville. 


\section{Sobre interdiscursividade: semiótica e AD francesa em diálogo}

A discussão em torno da interdiscursvidade é um ponto em comum em diferentes teorias que lidam com o discurso. Nesse âmbito, a título somente de menção, citamos os estudos de Bakhtin, relativos ao dialogismo, mas também, para citar alguns outros, as ideias de "arquitexto" ou "palimpsesto", de G. Genette; de "heterogeneidade", em Authier-Revuz; e, num terreno mais estrito à Análise do Discurso Francesa $\mathrm{e}$ às ideias de Dominique Maingueneau, o postulado do primado do interdiscurso, que assim é visto pelo autor: "Nossa própria hipótese do primado do interdiscurso inscreve-se nessa perspectiva de uma heterogeneidade constitutiva, que amarra, em uma relação inextricável, o Mesmo do discurso e seu Outro." (2008, p. 31)

Nesse âmbito, podemos dizer que a semiótica de base greimasiana, também uma teoria do discurso, sempre foi vista como demasiadamente voltada para o texto ou, em outras palavras, para uma análise interna, o que se daria em detrimento de uma análise externa, que a interdiscursividade parece pressupor. Entretanto, isto precisa ser melhor entendido, o que implica em se atentar para o fato de que não há uma total ausência de trabalhos de semioticistas refletindo sobre o assunto. Além dos escritos de Barros e Fiorin (1999), Fiorin (2002 e 2006), Discini (2003) e Lopes (1999), refletindo de alguma forma sobre o tema, temos também o que foi proposto por Saraiva (2012), cujas ideias, em diálogo com esses e outros autores, servirão para mostrarmos apontamentos metodológicos necessários para a realização de uma aproximação entre as duas áreas. Comecemos, assim, tratando do modo como a semiótica concebe enunciação e como a área vê esse conceito, tendose em conta também a questão da interdiscursividade, e pontos relativos ao conceito de ethos e a relações entre texto e contexto.

Segundo assinala Saraiva (2012), o modo semiótico de conceber o ato enunciativo preconiza que este não pode prescindir de um centro de discurso, de uma espécie de corpo-que-sente-e-percebe e de um agenciador dos valores sócio-históricos convocados e resentidos no próprio processo de enunciação. A enunciação é vista, 
assim, como o ato linguageiro que constrói, ao mesmo tempo, enunciado e sujeito enunciante, e ambos são constituídos na tensão entre o corpo, como centro sensível do discurso, e os influxos do contexto sócio-histórico, isto é, na tensão entre o individual e o social, por meio da práxis enunciativa.

Importante é frisar que, nos termos como ele é aqui compreendido, a partir da arquitetura geral da semiótica francesa, o corpo constitui um sincretismo entre sujeito e objeto, calcado na identidade destes dois actantes, um contínuo tensivo-fórico depreensível pela análise semiótica do percurso gerativo dos sentidos num texto ou num conjunto de textos, um campo de presença, enfim. Como diz Zilberberg (apud Tatit, 1997, p. 41), “o corpo é sempre o centro, está sempre no centro e é nesse sentido que nós o caracterizamos como extenso: ele dirige o processo perceptivo; onde quer que se encontre, o corpo ocupa o mundo que o engloba".

Essa maneira de conceber a enunciação está ligada a preocupações que a semiótica passou a ter principalmente a partir da introdução da temática das paixões na teoria e da publicação do livro Semiótica das paixões (1993). É por se levar em conta essa dimensão passional que, no dizer de Tatit (1997) a seguir, aparece a menção a essas questões relativas ao corpo. Vejamos:

Nossos discursos cotidianos promovem, de certa forma, em nome de uma eficácia de comunicação, a conversão do corpo como totalidade e continuidade fórica em desigualdades e dependências (elementos de reintegração) a que chamamos 'sentido'. A semiótica da ação traduziu as relações de dependência em determinações modais descontínuas, ou seja, em modalizações. A semiótica das paixões revelou, em contrapartida, que as tensões fóricas continuam participando do discurso, mesmo após a discretização cognitiva, em forma de modulações contínuas que transparecem na superfície do texto, testemunhando a onipresença do corpo que sente. (p. 43)

O importante a se notar é que, por apresentar essa dimensão de totalidade, esta noção de corpo, tal como a concebe a semiótica, pode ser aproximada da de ethos, presente na tradição retórica e redimensionada por Maingueneau (1995). Em Discini (2003), a autora, que investiga a questão do estilo, apresenta posicionamentos 
que visam mostrar como o efeito de ethos e de corpo, noções correlatas, são construídos, para um enunciatário, numa totalidade discursiva, que supõe, portanto, uma relação entre diferentes textos. $\mathrm{O}$ trecho a seguir ilustra isso:

Importa ratificar um sistema, construído na imanência do sentido da totalidade. Sistema pressupõe conjunto de regularidades, ou uma homogeneidade regrada que, por sua vez, pressupõe uma norma, enquanto recorrências de procedimentos na construção do sentido de uma totalidade. $\mathrm{O}$ enunciatário, assim normatizado, incorpora a cada dia um mesmo ethos, assume a cada dia o reconhecimento de uma identidade, o que lhe dá prazer; confirma e renova descobertas, firmando um olhar sobre o mundo, na reconstrução de cada totalidade. Temos, então, na enunciação, um sujeito (S1), o enunciador, que leva outro (S2), o enunciatário, a querer e dever entrar em conjunção com o valor do valor de uma totalidade. Trata-se de um querer contínuo, provocador de um dever, também contínuo; querer e dever-fazer e ser. Essa aspectualização narrativa pela continuidade firma, no discurso, a unidade do ethos, enquanto enunciador que define um corpo, um modo de ser no mundo, e enquanto enunciatário que incorpora esse corpo. (p. 61-62)

Corroboramos o ponto de vista de Discini (2003), para quem o ethos, como modo de dizer, e o corpo, como figura suporte deste modo de dizer, podem ser apreendidos a partir do texto-enunciado, ou de um conjunto de textos-enunciado, desde que se tome como parâmetro o espetáculo da interdiscursividade simulada no conteúdo efetivamente manifestado.

Discini (2003), ao dar tratamento a questões de estilo, tema de sua tese de doutoramento, nada vê que impeça, assim como nós, uma efetiva aproximação entre a perspectiva da semiótica discursiva e a da análise do discurso francesa. Também Lopes (1999), autor de uma tese que propôs uma aproximação entre ambas as áreas, não identifica óbice para tal posicionamento. $\mathrm{Na}$ verdade, ao abordar o assunto em seu trabalho de tese, refere-se ao Maingueneau de Genèses du discours (1984) como "um vizinho da semiótica".

Cremos, mesmo, ao mostrarmos esses pontos, que as abordagens da semiótica discursiva e da análise de discurso francesa 
são compatíveis, ou melhor, complementares. Na nossa forma de ver, ao circunscrever um espaço discursivo, no qual posicionamentos serão investigados, o pesquisador está criando uma totalidade discursiva, que não escapa, pelo menos neste momento, de apresentar um dentro e um fora, por mais que isto desagrade a quem postula, de forma radical, o primado da interdiscursividade. Esta, na verdade, constitui um complexo tão reticulado que sua apreensão sempre é parcial, condicionada às variáveis semióticas que se elegem como parâmetros constituidores dos textos, que, com efeito, são.

$\mathrm{Na}$ verdade, e trazendo nossa discussão para termos de feitio mais epistemológico e metodológico, pode-se dizer mesmo que a organização de um corpus implica, no próprio ato de sua constituição, uma isotopia (inter)discursiva, que finda por justificar por que o corpus compreende uns textos e não outros. Afinal de contas, subjacente à seleção de textos para análise está a questão da sua pertinência, e esta só pode ser medida em função de um princípio unificador como regra de descrição, conforme ensina Greimas e Courtés ([1979] s/d).

Por outro lado, quando se procura abordar o sujeito enunciante, seja numa totalidade de discurso, como no caso do estilo, seja no caso de uma contraposição entre autores, como no caso da oposição entre humanismo devoto e jansenismo, não se pode desprezar o contexto sócio-histórico, porque as estruturas de significação contidas no(s) texto(s) analisado(s) não cessam de convocar o contexto em que elas se forjaram. Portanto, texto e contexto estão em constante interação e separá-los, para efeito de análise, não significa, na maioria das vezes, considerá-los independentes.

Fiorin (2002), por exemplo, tece críticas aos pesquisadores que, de um lado ou de outro da "contenda" entre semioticistas e analistas do discurso de orientação francesa, reiteram o dizer de que os primeiros realizam uma análise interna, e os segundos, uma análise externa. Para ele, os termos análise interna e análise externa são muito ruins, porque podem dar a entender que o primeiro tipo de análise apenas se ocupa do aspecto linguístico, e o segundo, dos aspectos extralinguísticos. $\mathrm{Na}$ verdade, isto não ocorre, pois ambas as abordagens são linguísticas, na medida em que se ocupam da constituição do sentido, e diferem quanto ao foco, isto é, à importância dada aos mecanismos intradiscursivos ou 
interdiscursivos. Transcrevemos abaixo o comentário conclusivo de Fiorin (2002) acerca dos embates entre as duas abordagens discursivas, por considerarmo-lo extremamente sensato e coerente:

Durante muito tempo, partidários de uma ou de outra teoria trocaram uma série de "acusações". Os que se ocupavam predominantemente dos aspectos intradiscursivos foram tachados de reducionistas, dizia-se que eles ignoravam a História, que tinham uma visão empobrecedora do texto. Por outro lado, dizia-se que os que trabalhavam com as relações interdiscursivas eram cegos para os mecanismos de estruturação do texto, não reconheciam a especificidade linguística do discurso. Na verdade, as desconfianças mútuas não precisariam existir, já que, de um lado, não se pode exigir que uma teoria explique fatos que estão fora de seu escopo explicativo, de outro, as teorias do discurso, ao ressaltar os mecanismos intradiscursivos ou interdiscursivos, estão trabalhando com aspectos complementares da textualização e não com ângulos excludentes na abordagem do uso linguístico. (p. 41)

Segundo Fiorin (2002), as duas abordagens têm um caráter complementar, e, mais do que isto, a nosso ver, uma abordagem pressupõe a outra, já que não se concebe fazer uma análise interna do texto sem que se leve em consideração dados de natureza interdiscursiva, tampouco se concebe realizar uma análise interdiscursiva sem que se parta dos dados efetivamente presentes nos textos analisados. A diferença entre as abordagens é, então, de foco, e boa parte das razões motivadoras de disputa entre seus partidários, em verdade, não existe.

Diante de tais colocações, parece-nos não haver razão para separar texto e contexto de produção, a não ser que, por contexto, entenda-se a situação "concreta" em que se dá a realização de um discurso e, por texto, apenas a expressão que manifesta o conteúdo de um conjunto significante. Esta separação, é, com efeito, um equívoco. Não há contexto que não seja produto de interpretação, isto é, contexto "semiotizado", já de alguma forma "lido". O que ocorre, de fato, é que as grandezas co-presentes em um dado discurso apresentam-se sob diversos modos de existência: seja de um ponto de vista em que se relacionam à língua como sistema (em termos semióticos, como virtualidade ou potencialidade), seja 
levando-se em conta sua colocação em discurso (em termos semióticos, a língua atualizada ou realizada), o que abre o texto para o contexto em que este último se forjou.

Em outras palavras, e trazendo o modo como um semioticista vê a questão, tomando o pronunciamento de Fontanille (1998) como exemplo, vemos este autor dizer que "o texto é, para o especialista das linguagens - o semioticista -, aquilo que se dá a apreender, o conjunto dos fatos e dos fenômenos que ele se presta a analisar" (p. 79) e "o discurso é uma instância de análise na qual a produção, isto é, a enunciação, não poderia ser dissociada de seu produto, o enunciado" 2 (p. 81). Isto ainda pode ser complementando com outro trecho de Fontanille (1998), segundo o qual:

Com efeito, o ponto de vista do discurso neutraliza a diferença entre texto e contexto; adotar o ponto de vista do discurso é admitir, ao mesmo tempo, que todos os elementos que concorrem para o processo de significação pertencem por direito ao conjunto significante, quer dizer, ao discurso, quaisquer que eles sejam. Em poucas palavras, é apenas o ponto de vista do texto que "inventa" a noção de contexto. (p. 87)

Todavia, o manifestado é ponto de partida para toda e qualquer investigação. O que queremos dizer é que é o texto, e sempre o texto, que se presta à análise, mesmo que seja na sua dimensão cultural: o texto da cultura. É o texto, na qualidade de unidade significante manifestada, que permite acesso ao discurso em sua imanência e ao interdiscurso no qual ele foi forjado. Assim, se se quiser reconstituir o(s) sujeito(s) individual(is) ou coletivo(s) de uma totalidade de discurso, no caso do estilo, como é o objetivo de Discini (2003), ou se quiser estabelecer uma relação polêmica entre

\footnotetext{
${ }^{1}$ Le texte est (donc), pour le spécialiste des langages - le sémioticien - ce qui se done à appréhender, l'ensemble des faits e des phénomènes qu'il s'apprête à analyser".

2 Le discours est (donc) une instance d'analyse où la production, c'est-à-dire l'énonciation, ne saurait être dissociée de son produit, l'énoncé.

${ }^{3}$ En effet, le point de vue du discours neutralise la différence entre texte e contexte; adopter le point de vue du discours, c'est admettre d'emblée que tous les éléments qui concourent au procès de signification appartiennent de droit à l'ensemble signifiant, c'est-à-dire au discours, et quels qu'ils soient. Bref, c'est le point de vue du texte seul qui "invente" la notion de contexte.
} 
diferentes autores, o ponto de ancoragem é o texto. É nele que se podem encontrar os indícios seguros de um sujeito que enuncia.

Outros autores da semiótica também tocam na questão. Lembremos a esse respeito Landowski ([1989] 1992, p. 167), para quem a enunciação é "o ato pelo qual o sujeito faz o sentido ser" e o enunciado é "o objeto cujo sentido faz o sujeito ser". Outro exemplo é Coquet (1997), que não pensa de outro modo. No avant-propos de seu livro La quête du sens, ele afirma que, premido entre o serprojetado e o ser-para-além-do-mundo, "o discurso, reconectado às instâncias discursivas, comporta todas as instruções das quais o analista necessita para guiar, de outro modo, a busca do sentido" 4 .

No que tange a esta questão, continuamos a fazer eco a Discini (2003), quando advoga a ideia de que o estilo deve ser buscado "na configuração de uma totalidade de discursos enunciados" (p. 28), num percurso que vai do objeto (o enunciado) ao sujeito (da enunciação), exatamente como sugerira Greimas (1974). O sujeito aqui, por só poder ser depreendido a partir de uma pluralidade de textos, se realiza no ator da enunciação, como uma imagem-fim, um ethos do sujeito responsável por uma totalidade de discursos efetivamente enunciados.

Desse modo, se interpretamos corretamente a autora, a identidade de um ator discursivo, individual ou coletivo, se forja na interdiscursividade, é indubitavelmente dialógica, e sua reconstituição pode ser realizada a partir dos discursos efetivamente enunciados, tomados como uma totalidade discursiva, podendo isso ser aplicado tanto para as questões relativas ao estilo, quanto para relações de interdiscursividade entre enunciadores diferentes. É por isso que todo enunciador, para a autora, representa uma imagem-fim de si: "essa imagem-fim, simulacro reflexivo, ou seja, imagem constituída do ator para si mesmo, é também um simulacro héteroconstituído, supondo a visão que tenho do outro, bem como a visão que penso que o outro tem de mim" (2003, p. 29), numa visão análoga à de Landowski ([1997] 2002).

Concluímos, pois, esta primeira parte, citando o trecho abaixo, mais uma vez a partir de Discini (2003), em que se evidencia

\footnotetext{
${ }^{4}$ (...) le discours, rapporté aux instances énoçantes, comporte toutes les instructions dont l'analyste a besoin pour mener autrement la quête du sens (COQUET, 1997, p. 18).
} 
o papel do exame das configurações discursivas, não só na depreensão do ator da enunciação (sujeito epistemológico transdiscursivo) de uma totalidade de discursos enunciados, mas também nas relações interdiscursivas constitutivas de todo enunciado.

Em cada configuração discursiva, detectam-se, neste caso: um núcleo figurativo comum; invariantes temáticas; variações figurativas; variações temáticas; papéis figurativos, sendo que estes últimos se constituem por uma "forma temático-narrativa". Trata-se de uma configuração discursiva e de uma configuração temática, entre as quais despontam isotopias, figurativas e temáticas, juntamente com papéis figurativos. Nestas isotopias figurativas e temáticas e nesses papéis configurativos, firma-se a recorrência e firma-se a unidade, mas firma-se também o diálogo, pois daí desponta a convergência ou a divergência com as vozes de um dado contexto sócio-histórico. (p. 65)

Extrai-se desta passagem a confirmação de que o exame das configurações discursivas constitui uma via de acesso tanto para a (re)construção de uma persona transdiscursiva de uma totalidade de discurso quanto para a (re)constituição parcial do espaço discursivo no e pelo qual ela se forjou. O raciocínio dá conta não somente, portanto, das questões de ethos relativas à depreensão de um estilo, que estaria vista aí como uma relação interdiscursiva entre as obras de um mesmo autor, ou de uma espécie de "autor coletivo", mas também no próprio diálogo (polêmico ou não) que se possa estabelecer entre um discurso e, por exemplo, uma tradição a que se liga esse discurso, ou numa relação polêmica tal como acontece entre o discurso humanista devoto e o jansenista.

Em suma, a semiótica diz que enunciar é já tomar posição e assumimos que essa maneira de conceber pode ser vista de maneira complementar ao modo como análise do discurso francesa aborda o discurso. Enunciar é, então, tomar posição em relação a um campo de presença em cujo centro se encontra um corpo-que-sente-epercebe, e posição em relação ao imenso corpo de enunciações já realizadas. Com efeito, o sujeito que enuncia marca posição quanto às grandezas que são convocadas para o discurso, quer sejam elas diretamente ligadas ao corpo-que-sente-e-percebe, quer elas estejam 
vinculadas aos produtos do uso potencializados pelas enunciações anteriores.

\section{Comte-Sponville vs. Kierkergaard}

Antes de passar para a relação específica de contraposição entre os dois filósofos que serão matéria de análise, achamos pertinente dar dois exemplos, a bem de deixar mais claro ao leitor, do que seriam esses "produtos de usos potencializados por enunciações anteriores", tomando já esses elementos em relação ao discurso de André Comte-Sponville. Um exemplo tem um caráter ilustrativo e remete ao dicionário como "discurso sobre o uso de uma dada cultura" (GREIMAS; FONTANILLE, 1993, p. 101), tal como, por diversas vezes, em suas obras, Greimas o considerou; o outro, remete à tradição do discurso filosófico. Vejamos o primeiro exemplo, pondo em discussão um ponto central de nossa reflexão: o lexema desespero.

Se formos ao Houaiss (2009, p. 650) - e aqui reiteramos o caráter simplesmente ilustrativo desse procedimento, já que seria mais adequado tratar do lexema a partir de um dicionário de língua francesa, língua de Comte-Sponville -, veremos os seguintes segmentos definicionais do que é entendido como desespero: primeiro, "estado de profundo desânimo de uma pessoa que se sente incapaz de qualquer ação; desalento"; segundo, "estado de consciência que julga uma situação sem saída; desesperança;" e, no terceiro segmento, "estado de desânimo, de sofrimento a que se sujeita uma pessoa devido a um excesso de dificuldades e de aflições; aflição, angústia, exasperação".

Podemos dizer, em contato com esses enunciados, que o lexema "desespero" é visto de modo disforizado, como negação de outros estados, o que se marca por prefixos como "des", presentes em "desesperança", "desalento" e no próprio termo "desespero". Dentro dessa mesma lógica, encontram-se ainda julgamentos de intensidade, ou seja, termos que mensuram o que é a "justa medida" ou o que é o "demais" ou o "insuficiente", como no caso das palavras "profundo", "excesso".

O que queremos frisar, nesse gesto de consulta, é o fato de que parece haver, nesses diferentes segmentos, um posicionamento 
mínimo, um ponto de vista que é o responsável pela cristalização de conotações em torno de um lexema e é este fator que faz com que Greimas considere o dicionário como discurso que de alguma forma representa uma visão de uma cultura. $\mathrm{O}$ dicionário, portanto, veicula estabilizações de concepções sobre o lexema, concepções estas que podem ou não ser convocadas em um discurso específico.

De todo modo, no que se refere a esse ponto, o dicionário se expressa como um elemento a estabelecer uma interdiscursividade mínima em relação com outros discursos, uma vez que "cristaliza", reproduz e representa concepções do "senso comum" sobre a paixão. Mas podemos pensar também essa questão levando em conta o que se entende como uma "paixão da alma" no discurso filosófico, o que indicia também algo que apontamos, na seção anterior, ou seja: a enunciação não é só um ato "novo" e singular a cada vez que ocorre, mas também "práxis enunciativa", pois pressupõe uma interação com os produtos de enunciações já anteriormente realizadas em um determinado espaço discursivo.

No que tange ao discurso filosófico, parece haver também uma tendência disforizante no trato das "paixões da alma" em geral, pelo menos dá indícios disso um autor como Didi-Huberman: "Muitos filósofos falariam da emoção como algo unicamente negativo: a emoção não é isso, não pode aquilo etc. Kant, por exemplo, disse que a emoção é apenas um 'defeito da razão', uma 'impossibilidade de refletir' e até mesmo uma 'doença da alma" (2016, p. 21-22). A bem de ilustrarmos isso, tracemos outros exemplos, mostrando outros filósofos que versaram sobre a paixão do desespero. Comecemos por Espinoza, no livro Ética:

(...) Pois a Esperança é nada outro que a Alegria inconstante originada da imagem de uma coisa futura ou passada, de cuja ocorrência duvidamos. O Medo, ao contrário, é a Tristeza inconstante originada da imagem de uma coisa duvidosa. Além disso, caso a dúvida seja suprimida desses afetos, da Esperança faz-se a Segurança, e do Medo, o Desespero (...) (ESPINOZA, 2015, p. 269)

Novamente aparece a definição do desespero como uma privação de esperança. Se formos a Cícero, o mesmo acontece, quando vemos este autor assim afirmar como tal paixão era vista pelos estoicos: “(...) um desgosto em que não existe qualquer 
esperança de melhoria" (2014, p. 227). Em Descartes, também algo parecido, acrescido de discussão sobre outras paixões, como o medo ("temor"):

Porém, quando consideramos se há muita ou pouca probabilidade de conseguir o que se deseja, aquilo em que se nos afigura existir muita estimula em nós a esperança, e aquilo em que se nos afigura existir pouca estimula o temor, de que o ciúme constitui uma espécie. Quando a esperança é máxima, muda de natureza e chama-se segurança ou confiança, e, ao contrário, o máximo temor transforma-se em desespero. (DESCARTES, 1999, p. 144)

Elencando essas diferentes definições, notamos que André Comte-Sponville $(2002,2006)$ no que tange ao desespero e em relação a essa tradição, apresenta um posicionamento específico. O impacto gerado por Comte-Sponville é que seu discurso euforiza tal paixão, ou seja, a vê de modo positivo, apresentando um discurso "desviante" ou um tanto inusitado quanto ao que consta nas conotações de viés disfórico que possuem os dicionários e os textos desses filósofos. Diante disso, nos perguntamos: já que vemos aí também toda uma dimensão interdiscursiva ser convocada, onde se situariam as raízes semânticas e discursivas dessa diferença?

É essa relação de interdiscursividade e de polêmica estabelecida pelo autor que se dá, como já antecipamos neste texto, de modo similar ao que foi constatado por Maingueneau em sua análise sobre o discurso humanista devoto e o discurso jansenistas: uma contraposição de semas que se cifram a partir do posicionamento de Comte-Sponville frente ao discurso de Kierkergaard. O que ressalta com mais clareza é o claro confronto do filósofo francês com o filósofo dinamarquês, que, tal como o concebe Comte-Sponvile, disforiza o desespero. Vejamos um trecho em que isso aparece:

Sim, é um Tratado do desespero que empreendo aqui; mas não como doença mortal, conforme o título que Kierkergaard lhe deu. Quero escrever um tratado do desespero como saúde de alma, e que estaria para a esperança assim como a serenidade está para o medo". (COMTE-SPONVILLE, 2006, p. 16) 
Diante disso, se pensarmos que a paixão do desespero é vista pelos outros filósofos como uma paixão da quebra de expectativas, em que o sujeito vê-se desprovido de uma fé, sem esperança, veremos o motivo de outros semas serem convocados no centro das reflexões do filósofo francês. São esses elementos que indiciarão os semas que estão em jogo nesse embate. Quanto a este ponto, vemos uma frase central do autor: "'O contrário de desesperar é crer', diz Kierkergaard. Pode-se inverter: o contrário de crer é desesperar." (2006, p. 17-18).

É interessante ver aqui o filósofo "brincar" com uma lógica de contrários, colocando os dois verbos em uma estrutura elementar, em oposição. Obviamente, há uma concepção de desespero subjacente, implicada no pensar de cada um desses autores. A alternância de predicação aí não se dá por acaso e revela, em verdade, uma relação de negação do /crer/ por parte de ComteSponville. Este filósofo diz, portanto, que ao invés de se negar o desespero e afirmar o "crer", tal como diz ele acontecer no discurso de Kierkergaard, deve-se negar tal verbo e afirmar o "desesperar":

Figura 1 - Dêixis opostas: Comte-Sponville vs. Kierkergaard

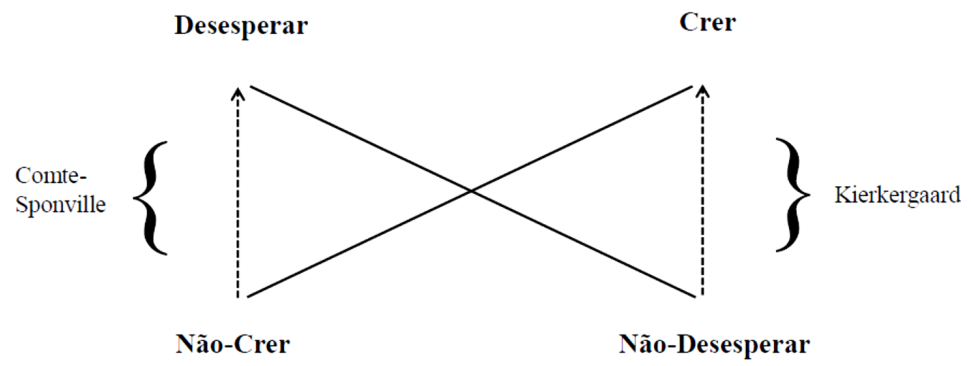

Fonte: extraído de Oliveira $(2019$, p.57)

A sutileza que há na simples alternância é que ela indicia uma oposição entre dois percursos contrários de visões sobre o desespero. É esta diferença que pode explicar como a configuração do desespero possa ser vista de modo eufórico pelo filósofo francês. Em André Comte-Sponville há de modo muito claro uma desvalorização 
(disforização) de qualquer atitude de crença e expectativa que tenha motivação prospectiva. Daí que a esperança seja algo "negativo" no discurso deste autor e que ele dedique um livro de mais de 300 páginas em busca justamente de negar atitudes de ordem "utópica" e "idealista" do homem. Vejamos outro trecho:

(...) É o grau zero da esperança. Nada mais, nada menos. É uma espécie de estado sem futuro [pois não há futuro que não seja de esperança], cuja possibilidade e cujas consequências trata-se, precisamente, de avaliar. O desespero é o próprio presente. Em outras palavras: a eternidade de viver." (COMTEM-SPONVILLE, 2006, p.15)

Há uma clara dimensão temporal analisada pelo filósofo materialista. Podemos ver, a partir dessas colocações, o autor se voltar para uma negação do que se afirma como uma atitude marcada pela prospectividade, que é, em suma, uma característica temporal de paixões como a espera e a esperança. Assim, além de o filósofo francês definir o desespero também em função da negação dessas duas paixões, trata-o de modo euforizante, uma vez que recobre semas contrários a semas como/prospectividade/, /passividade/, que são disforizados pelo autor:

(...) Não nos importa que uma utopia tome o lugar de outra: a mesma cilada sempre renasce, a cilada da esperança e da fé. O futuro é a terra prometida de todas as alienações. (...) Tudo cabe no futuro. Amanhã, Deus e Stálin barbearão de graça... A utopia é o ópio do povo. Trata-se de aprender a desesperar. (COMTE-SPONVILLE, 2006, p.175)

A contundente afirmação do desespero fez surgir em nós a pergunta de se tal reflexão versava sobre a mesma paixão. Interessante é que por um momento, o autor faz até mesmo algumas considerações sobre o uso da palavra: "Essa palavra, porém, me incomoda um pouco, confesso, pelo que evoca de aparentemente negativo ou triste, por suas conotações de melancolia (...)" (COMTE-SPONVILLE, 2006, p.16), e pensa até mesmo em usar a palavra "inesperança", o que, porém, acentuaria a dimensão de simples negação da esperança em seu raciocínio e caracterizaria que, em verdade, o filósofo também estaria tratando o desespero como 
contraditório da esperança, numa visão um tanto comum à tradição dos filósofos, que trataram das paixões predominantemente pela negação.

Mas se formos mais a fundo nessa contraposição feita pelo autor, veremos que, em verdade, a atitude de Comte-Sponville, além de negar a espera e a esperança, afirma a ação, o que está relacionado com suas concepções materialistas baseadas no marxismo e também a um posicionamento existencialista de base sartriana ${ }^{5}$. E é neste momento que a estrutura semântica "se fecha" e à negação da espera e da esperança se segue a afirmação do desespero, via o sema /atividade/, em contraposição a /passividade/: "Porque o desespero, mesmo o mais neutro, nunca é um estado original; sempre supõe a força prévia de uma recusa", "A esperança é primeira; logo: necessário perdê-la. O des-espero indica essa perda, que não é a princípio um estado, mas uma ação." (COMTESPONVILLE, 2006, p.16)

São essas articulações sêmicas que nos permitem organizar um microuniverso semântico sobre o qual gira todo o livro de Comte-Sponville, em que a atividade de recusa se coloca como característica do sujeito em desespero. É a oposição à passividade, a inquietude do sujeito desesperado e a afirmação da "ação" (/atividade/, pois), a não espera por um porvir, que fazem o filósofo ver tal paixão como eufórica e utilizá-la como mote para uma reflexão filosófica sobre subjetividade, política e estética, distribuídas nos três capítulos de sua obra.

Vejamos organizados no esquema a seguir esses semas postos em jogo, lembrando que o que se atribui a Kierkergaard é relativo à tradução que Comte-Sponville realiza ao tomar posição em relação ao discurso do dinamarquês, o que passa por um gesto de negação e de posterior afirmação de semas:

\footnotetext{
${ }^{5}$ Quanto à relação entre desespero e ação sob a ótica existencialista, indicamos o texto de Sartre (1987), em que o autor afirma essas posições.
} 
Figura 2 - microuniversos em contraposição

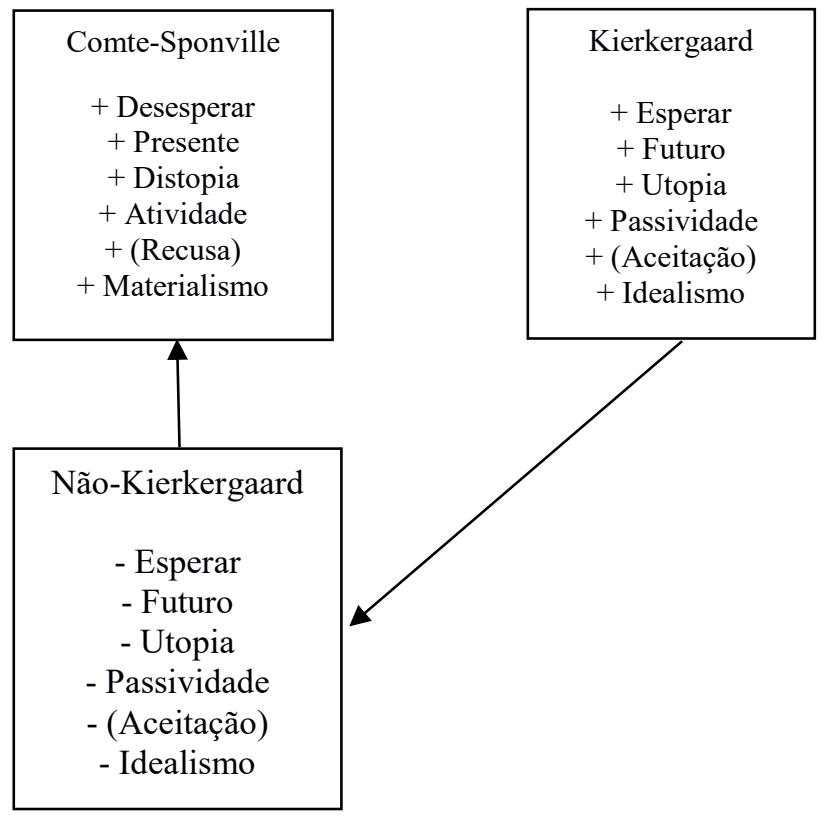

Fonte: elaboração nossa

No local do verbo "esperar", poderia estar "crer" novamente, escolhemos o primeiro verbo só para ficar mais clara a relação de oposição que se estabelece. Em suma, a relação de interdiscursividade que vemos ser endossada por Comte-Sponville se dá pautada justamente numa relação de contrariedade com um simulacro identitário do filósofo Kierkergaard que ele próprio, Comte-Sponville, traduz. A partir de um posicionamento em face do outro, ou seja, o discurso do filósofo dinamarquês (e da própria tradição filosófica), o mesmo, a identidade do discurso do filósofo francês, se faz. 


\section{Para concluir}

Buscamos no presente texto mostrar que a Análise de Discurso Francesa e a Semiótica Discursiva podem ser vistas de modo complementar na consecução de uma análise. Para demonstrálo, escolhemos tratar desses termos a partir do discurso de um filósofo contemporâneo, que versou sobre o desespero, e que tratou desta "paixão da alma" como um conceito, um tema. Mas vemos outros caminhos de diálogo entre as áreas também no que tange à questão do ethos nos discursos "apaixonados", ou seja, discursos que não teorizam ou conceituam uma paixão, mas que são passionais, algo muito comum em discursos polêmicos.

Em semiótica, os estudos de Discini (2003, 2015), um deles já mencionado por nós no decorrer do texto, já tem ido nessa direção, uma vez que a autora pensa o ethos também como corpo justamente para dar conta da sua dimensão passional. Os estudos de Barros (2008, 2016), que tratam de paixões como a do ódio em discursos intolerantes, também exploram essas questões, visando dimensionar o modo como se constrói esse ethos "intolerante".

Por outro lado, também nesse sentido, mas pensando agora numa apropriação da análise do discurso francesa de algumas categorias da semiótica, e não o contrário, seria frutífero, a nosso ver, o diálogo de uma autora como Amossy (2014) com a semiótica das paixões, justamente porque, em sua abordagem sobre a polêmica, a autora está constantemente trazendo a questão das paixões. De ambos os lados, há um interessante caminho a se traçar na busca de analisar discursos que envolvem essas questões, muito presentes em nossas sociedades atuais.

\section{REFERÊNCIAS}

AMOSSY, R. Apologie de la polémique. Paris: PUF, 2014.

BARROS, D. L. P. de. Estudos discursivos da intolerância: o ator da enunciação excessivo. Cadernos de Estudos Linguísticos (UNICAMP), v. 58, p. 7-24, 2016. Disponível em: $<$ https://periodicos.sbu.unicamp.br/ojs/index.php/cel/article/view/8646151>. Acesso: 30/11/2019. 
BARROS, D. L. P. de. A identidade intolerante no discurso separatista. Filologia e Lingüística Portuguesa, v. 9, p. 147-167, 2008. Disponível em: $<$ http://www.revistas.usp.br/flp/article/view/59777>. Acesso: 30/11/2019.

BARROS, D. L. P. de e FIORIN, J. L. Dialogismo, polifonia, intertextualidade. São Paulo: EDUSP, 1999.

COMTE-SPONVILLE, A. Tratado do Desespero e da Beatitude. Trad. de Eduardo Brandão. São Paulo: Martins Fontes, 2006.

COMTE-SPONVILLE, A. O alegre desespero. Tradução de Maria Leonor F. R. Loureiro. São Paulo: Editora UNESP; Belém, PA: Editora da Universidade Estadual do Pará, 2002.

DESCARTES, R. As paixões da alma. São Paulo: Nova cultural, 1999.

DIDI-HUBERMAN, G. Que emoção! Que emoção? Trad. de Cecília Ciscato. São Paulo: editora 34, 2016.

DISCINI, N. Corpo e estilo. São Paulo: Contexto, 2015.

DISCINI, N. O estilo nos textos. São Paulo: Contexto, 2003.

ESPINOSA, B. Ética. Trad. de Grupo de Estudos Espinosanos. São Paulo: EDUSP, 2015.

FIORIN, J. L. Teoria e metodologia nos estudos discursivos de tradição francesa. In: SILVA, D. E. G. da e VIEIRA, J. A. Análise do discurso: percursos teóricos e metodológicos. Brasília: Plano/UnB, 2002, p. 39-74.

HOUAISS, A.; VILLAR, M.S. de. Dicionário Houaiss da língua portuguesa. 1 ed. Rio de Janeiro: Objetiva, 2009.

KIERKERGAARD, S. O desespero humano. Trad. de Adolfo Casais Monteiro. São Paulo: Editora Unesp, 2010.

LOPES, P. E. A desinvenção do som: leituras dialógicas do Tropicalismo. São Paulo: Pontes, 1999.

MAINGUENEAU, D. Gênese dos discursos. Trad. de Sírio Possenti. São Paulo: Parábola Editorial, 2008. 
MAINGUENEAU, D. O contexto da obra literária. São Paulo: Martins Fontes, 1995.

MAINGUENEAU, D. Genèses du discours. Bruxelas: Pierre Mardaga, 1984.

OLIVEIRA, G. M. de. O percurso semiótico do desespero no romance Angústia, de Graciliano Ramos. Dissertação de Mestrado. Programa de Pós-Graduação em Linguística, Universidade Federal do Ceará, Fortaleza, 2019. Disponível em: $<$ http://www.repositorio.ufc.br/handle/riufc/41878>. Acesso: 30/11/2019.

SARAIVA, J. A. B. A Identidade de um Percurso e um Percurso de uma Identidade: um estudo semiótico das canções do Pessoal do Ceará. Fortaleza: EDUFC, 2012.

SARTRE, J.P. O existencialismo é um humanismo. Os Pensadores (Coleção). São Paulo: Nova Cultural, 1987. 